\title{
Reflexiones teórico-metodológicas sobre algunos dilemas en el estudio de prácticas sexuales clandestinas
}

\author{
Theoretical-methodological reflections on some dilemmas in the study of \\ clandestine sexual practices
}

\author{
Miguel Ángel Esparza Escalante \\ mianyel_30@hotmail.com \\ CONICET-Universidad Nacional de Catamarca, \\ Argentina \\ José Alberto Yuni \\ joseyuni@yahoo.com.ar \\ CONICET-Universidad Nacional de Catamarca, \\ Argentina

\section{Claudio Ariel Urbano \\ claurbano@hotmail.com \\ CONICET-Universidad Nacional de Catamarca, Argentina}

Cita sugerida: Esparza Escalante, M. A., Yuni, J. A. y Urbano, C. A. (2020). Reflexiones teórico-metodológicas sobre algunos dilemas en el estudio de prácticas sexuales clandestinas. Revista Latinoamericana de Metodología de las Ciencias Sociales, 10(2), e082.

https://doi.org/10.24215/18537863e082

Recepción: 09 Septiembre 2019

Aprobación: 13 Abril 2020

Publicación: 01 Diciembre 2020
Resumen: El artículo aborda algunas cuestiones dilemáticas de orden teórico-metodológico surgidas en el ejercicio de reflexividad propio de toda investigación social de orientación crítica. El estudio de prácticas sociales clandestinas ha concitado históricamente el interés de los investigadores por sus implicancias metodológicas y éticas. Las prácticas clandestinas que abordamos remiten a la sexualidad masculina, lo que agrega otra densidad a la investigación, especialmente en lo relativo al trabajo de campo y a la interpretación de la información. En la primera parte, el texto contextualiza la investigación que origina esta reflexión en términos conceptuales y la localiza en un espacio socio-cultural específico. Posteriormente, se explicitan algunas decisiones metodológicas que estructuran nuestra estrategia de abordaje del trabajo de campo desde el enfoque etnográfico. En la última parte, se contrastan algunas prescripciones metodológicas de investigadores del campo de los estudios de la sexualidad y de autores reconocidos del enfoque etnográfico, con registros extraídos de la bitácora del relevamiento en campo, elaborada en el proceso de observación participante efectuado en escenarios de prácticas sexuales clandestinas de hombres que tienen relaciones sexuales con hombres. Esta contrastación pretende mostrar las tensiones metodológicas que debe afrontar el investigador social que aborda un objeto connotado por la clandestinidad, así como algunas cuestiones dilemáticas de orden ético.

Palabras clave: Clandestino, Ética científica, Etnografía, Prácticas sexuales, Reflexividad.

Abstract: The article addresses some dilemmatic questions of a theoretical-methodological nature that arose in the exercise of reflexivity typical of all critically oriented social research. The study of clandestine social practices has historically attracted the interest of researchers for its methodological and ethical implications, the clandestine practices that we address refer to male sexuality, which adds another density to the research, especially in relation to fieldwork and the interpretation of information. In the first part, the text contextualizes the research that originates this reflection in conceptual terms and locates it in a specific socio-cultural space. Subsequently, some methodological decisions that structure our approach to fieldwork from the ethnographic approach are explained. In the last part, some methodological prescriptions of researchers 
in the field of sexuality studies and recognized authors of the ethnographic approach are contrasted, with records extracted from the field survey log, elaborated in the participant observation process carried out in clandestine sexual practices of men who have sex with men. This contrast aims to show the methodological tensions that the social researcher must face when dealing with an object connoted by clandestinity, as well as some dilemmatic questions of an ethical nature.

Keywords: Clandestine, Scientific ethics, Ethnography, Sexual practices, Reflexivity.

\section{INTRODUCCIÓN}

En este trabajo se plantea una serie de reflexiones teórico-metodológicas sobre los dilemas surgidos en un estudio sobre prácticas sexuales de hombres que mantienen sexo con hombres (en adelante HSH), prácticas connotadas por su carácter clandestino. Nuestro objetivo es interpelar algunas recomendaciones y prescripciones metodológicas de las metodologías de la investigación de las ciencias sociales, que entran en tensión a la hora de abordar un objeto de estudio signado por una doble lógica de abyección: la de tratarse de una práctica sexual considerada desviada y, a la vez, vinculada a contextos de clandestinidad. Por otra parte, las prácticas sexuales de HSH socavan los imaginarios de la masculinidad hegemónica, lo que les otorga un carácter aún más complejo.

Las cuestiones que han orientado nuestra práctica reflexiva siguen el hilo de algunos interrogantes. ¿Qué estrategias metodológicas facilitan el acceso a escenarios de prácticas sociales/sexuales clandestinas? ¿Cuáles son las dificultades que se presentan en el acceso a y permanencia en escenarios abiertos y públicos en estudios de sexualidad en los que se pretende reconstruir las prácticas en su contexto "natural"? ¿Qué tensiones se ponen en juego en la práctica de la investigación etnográfica y los requerimientos éticos de una investigación sobre sexualidad en situación de clandestinidad? ¿Qué adecuaciones éticas se requieren para hacer frente a la complejidad de la realización del trabajo de campo en escenario de clandestinidad mediante la observación participante?

Todos estos interrogantes atraviesan la totalidad del proceso metodológico ${ }^{1}$, lo que obliga a la realización de un sostenido esfuerzo de reflexividad en las diversas instancias de la investigación. En este artículo nos focalizamos en la descripción comprensiva de las diferentes tensiones que se generan en la accesibilidad al campo de las prácticas sexuales clandestinas, así como en las implicancias que ellas tienen en los modos de interacción y relación del investigador con los HSH en espacios clandestinos. En una primera parte se presenta una somera descripción de nuestra investigación, explicitando algunos aspectos que justifican los posicionamientos teóricos y metodológicos generales. En la segunda parte, se ofrece una caracterización del contexto socio-cultural en el que se desarrolla el estudio empírico. Esta descripción contextual permite ponderar los condicionamientos implicados en la materialidad de las prácticas sexuales clandestinas de $\mathrm{HSH}$, a partir de los cuales fue necesario desplegar estrategias metodológicas apropiadas y pertinentes a la naturaleza del objeto. Posteriormente se describen algunas tensiones relacionadas con las prescripciones regulatorias de la ética del investigador, en su contraste con los avatares de su inmersión y estancia en los escenarios sexuales clandestinos observados. Para llevar a cabo la descripción, se cotejan algunas propuestas metodológicas orientadas a regular aspectos éticos de la investigación social con diferentes escenas extraídas de los registros de campo. Por último, se presenta una breve reflexión sobre los dilemas que han surgido en la experiencia del trabajo de campo y que pueden significar un aporte para los investigadores de las sexualidades. 


\section{El MARCO DE NUESTRA INVESTIGACión}

Nuestro trabajo es parte de una investigación más amplia sobre prácticas sexuales clandestinas y factores de riesgo para la transmisión del VIH de hombres que sostienen prácticas sexuales con otros hombres. Uno de los ejes del trabajo se orienta a la caracterización de las prácticas sexuales clandestinas de los $\mathrm{HSH}$, entendiendo que la condición de clandestinidad es en sí misma una situación de riesgo psico-físico-social que incrementa el potencial de experimentar riesgos de contagio del VIH y otras enfermedades de transmisión sexual. En otras palabras, entendemos que la clandestinidad en la que se producen los encuentros sexuales de HSH promueve la realización de ciertas prácticas que potencialmente son de riesgo para la salud física.

En años recientes se ha revitalizado el interés por la sexualidad masculina, motivado principalmente por las perspectivas feministas críticas y radicales, que señalan que la lógica patriarcal y los mandatos heteronormativos no sólo configuran la posición subalterna de las mujeres, sino también la de otras masculinidades no hegemónicas, como las de gays y bisexuales. En menor medida, se han estudiado las prácticas sexuales de varones que se definen como heterosexuales, pero que en forma regular o esporádica mantienen encuentros sexuales con otros varones independientemente de su orientación sexo-genérica. Figari ha propuesto la categoría de heterosexualidad flexible para dar cuenta de este fenómeno (en Pecheny, Figari, Jones, 2008).

El origen de nuestra investigación se relaciona con el problema socio-sanitario del incremento de casos de VIH en mujeres heterosexuales, cuya vía de contagio fueron sus compañeros sexo-afectivos que adquirieron la enfermedad en encuentros sexuales con otros varones. De este modo, los registros epidemiológicos dieron cuenta del problema de la realización de determinadas prácticas sexuales de los varones heterosexuales, prácticas en las que se generan situaciones de riesgo para la transmisión del VIH.

La categoría de HSH fue creada por la OMS con fines epidemiológicos. En el trascurso de la epidemia del VIH en la década de los ochenta se encontró que muchos hombres que tenían relaciones sexuales con otros hombres no se identificaban como gays o bisexuales. Eso llevó a crear esta categoría, que permitía caracterizar un espectro más amplio de prácticas de riesgo y a identificar un grupo estadísticamente vulnerable. Guillermo Núñez efectúa una aproximación descriptiva al concepto:

La expresión HSH pretende definir una categoría de personas según una opción de comportamientos y no de la identidad cultural de un grupo social o de un individuo" (2002, p. 111). Es la opción de comportamiento, la práctica sexual, lo que da origen al concepto HSH, se nos dice. Los HSH, aclaran Manzelli y Pecheny, no son un grupo social con una identidad cultural o personal, es decir, no existen individuos o grupos socialmente identificado como HSH, se trata de una categoría epidemiológica (y del activismo) (Núñez, 2007, p.307).

La categoría HSH se construye a partir de la realización de ciertas prácticas sexuales y prescinde de la referencia identitaria que relaciona el comportamiento sexual con determinada orientación sexo-genérica. La categoría asimila el término hombre-masculino-varón y elude la referencia a la heterosexualidad, aunque no por ello el término evoca menos sus resonancias.

El sustrato de la autoidentificación como HSH es la heterosexualidad. La homosexualidad como identidad negativa y la bisexualidad como identidad de exploración permiten la afirmación de la propia hombría. En general, los HSH se consideran a sí mismos, antes que nada, varones. Ellos son los sujetos de la acción que mueve el encuentro y el contacto sexual con otros hombres, aunque esos otros se reconozcan como pares o como gays, bisexuales o transexuales.

Una aproximación psicológica señalaría el carácter paradojal de la concreción de una práctica sexual que revela una orientación hacia determinado objeto de deseo y cuyo sujeto actante rechaza cualquier forma de identificación con ella. Negación, represión, desplazamiento son categorías psicológicas que permitirían dar cuenta de los procesos psíquicos implicados en la configuración de la identidad y su expresión subjetiva. Sin embargo, estas no son las que cuestiones sobre las que focaliza nuestro proyecto, sino en las prácticas 
mismas, ya que allí se configuran condiciones y situaciones específicas de riesgo, algunas de ellas propias de su naturaleza clandestina.

\section{CoORdenADAS DE LOCALIZACión Y CONTEXTUALIZACIÓN DEL ESTUDIO}

La investigación se localiza en la provincia de Catamarca, situada en la región noroeste de la Argentina. Los escenarios de observación de encuentros sexuales entre HSH seleccionados para el trabajo de campo se ubican en la ciudad capital, San Fernando del Valle de Catamarca, llamada coloquialmente con el nombre de la provincia.

Según el Censo Nacional de Población y Vivienda del año 2010, la provincia contaba con una población total de 367.828 habitantes. La ciudad capital y otras dos localidades que conforman el conglomerado del Gran Catamarca cuentan con 198.841 habitantes, lo que representa el 54 \% del total de población de la provincia. Como puede observarse, se trata de una provincia con una fuerte concentración urbana en el Gran Catamarca y extensas regiones del norte provincial con muy baja densidad demográfica.

El Gran Catamarca se ubica en el Valle Central y, además de la concentración poblacional, condensa la mayor parte de los organismos estatales, universidad, etc. La principal actividad económica es el sector servicios, estrechamente relacionado con la administración pública provincial, nacional y municipal. A partir de la década de los setenta la agenda política local inauguró una serie de "operaciones modernizadoras" que provocaron fuertes transformaciones en los entornos, medios y modos de vida de la sociedad local. Ponce, Machado y Perea (2012) repasan los hitos de ese proceso como parte de una alianza cada vez más estrecha entre el Estado y el Mercado. A través de una serie de políticas orientadas a la "promoción del desarrollo" con diferentes instrumentos de regulación productiva, se produjo una reconversión del sistema productivo, cuyos ejes fueron la implantación de la minería extractivista a gran escala y el reemplazo de las formas tradicionales de agricultura por megaemprendimientos de monocultivos regionales (soja, olivo, jojoba, etc.). En esas décadas se acentuó el proceso de desruralización, se incrementó el conflicto social y se extendió la pobreza, especialmente en la población urbana (Ponce, Machado y Perea, 2012).

Además de la dimensión económica, el proceso de modernización pretendió la reconversión de ciertas tradiciones, atribuyendo los problemas del desarrollo a la persistencia de ciertos patrones culturales que operan como obstáculos. Los escasos estudios locales que han abordado sistemáticamente la dimensión sociocultural coinciden en señalar el carácter conservador de la sociedad. Ese conservadurismo se relaciona con el carácter estructurante de la religión católica en la construcción de sentidos y prácticas sociales. La impronta del catolicismo en la vida cotidiana se refuerza con el culto a la Virgen del Valle. Esta tradición religiosa es producto de una construcción que tiene cuatro siglos de presencia en el territorio. La imagen de la Virgen, denominada popularmente como "La morena", opera como un catalizador de las dinámicas del mestizaje que desde el período colonial expresan las conflictivas étnicas de la población “europea”, la negritud y la indianeidad en el contexto local (Guzmán, 2010).

La referencia a la religiosidad es relevante para comprender el contexto socio-cultural, en tanto que el dispositivo de la sexualidad aparece fuertemente estructurado por los mandatos de la moral católica. Por otra parte, el poder de los sectores católicos en la vida pública local se expresa en su injerencia en el discurso estatal. En la vida cotidiana es frecuente encontrar en todos los espacios institucionales (aun de los ámbitos que deben garantizar la laicidad) imágenes de la Virgen, ermitas o pequeños oratorios en los que los transeúntes "toman gracia”, realizan plegarias o colocan como adorno flores u otros objetos religiosos.

El Mapa de la Discriminación de Catamarca elaborado en el año 2012 entre el INADI y la Universidad Nacional de Catamarca ofrece indicios de las actitudes y prejuicios circulantes en la comunidad local. Al analizar los datos del índice de discriminación local, los autores señalan que las respuestas a ciertos reactivos denotan rasgos de una sociedad conservadora, con una tendencia a la estigmatización de los jóvenes y la discriminación de personas o grupos que se alejan de los mandatos de la moral cristiana. En lo que respecta a 
la sexualidad, el informe muestra niveles altos de rechazo hacia las personas trans, asociadas semánticamente con enfermedad, perversión, prostitución y pecado. Es menor la discriminación hacia las personas gays, asociadas a atributos estéticos (lindos, cuidados) o con ciertas capacidades (inteligentes, valientes). El mismo estudio registra también las actitudes de rechazo hacia las personas que profesan otras religiones, así como a políticas públicas orientadas al reconocimiento de la identidad de género u otras medidas de reconocimiento de derechos de las minorías sexuales.

El peso del discurso conservador religioso se ha hecho evidente en los últimos años, a partir del debate público sobre la implementación de la Ley de Educación Sexual Integral (ESI) en las escuelas de gestión estatal, la Ley de interrupción voluntaria del embarazo o las políticas sanitarias orientadas a la prevención del embarazo adolescente. En contrapartida, en las últimas décadas el acceso a los medios de comunicación y las políticas de inclusión y reconocimiento de la diversidad sexual permitieron la visibilización y la circulación abierta en el discurso público de estos temas.

El dispositivo de regulación de la sexualidad basado en la moral católica promovió el silenciamiento de otras formas de sexualidad, así como la condena del ejercicio de la sexualidad sin fines reproductivos. Por ello, en una sociedad conservadora, el mandato social prescribe que de eso no se habla; el discurso de la sexualidad sólo es público cuando reafirma la normalidad del binarismo sexual y sostiene la heteronorma. Esa prescripción produce la proscripción de discursos y prácticas sexuales disidentes, de lo que se murmura, lo que se dice, pero que no se reconoce.

En esta lógica de lo social, la moral conservadora activa fuertemente los mecanismos de regulación, vigilancia y control de las prácticas consideradas abyectas, lo que alienta comportamientos de represión y de prácticas correctivas. Ese mecanismo social de represión sexual opera a través de la culpa en lo individual, el miedo a la exposición de ser/estar visibilizado como anormal como castigo social y la estigmatización como marca pública de la condición disidente. Pero como en toda comunidad con fuertes procesos de represión sexual y moral sostenidos en principios morales, las prácticas clandestinas se intensifican y "las dobles vidas" se materializan en múltiples máscaras y opciones vitales.

Siguiendo esa lógica social, la resistencia de los HSH a identificarse con una identidad genérica explicaría la necesidad de sostenerse en cierto patrón de masculinidad, construido desde el ejercicio públicos de roles sociales heterosexuales (casarse, formar una familia, tener hijos, etc.). En ese marco, las prácticas de relacionamiento sexual con otros varones serían una licencia de la masculinidad hegemónica que mientras transcurran en la clandestinidad, se desarrollen en las sombras de lo permitido, pueden ser realizadas. Como veremos a continuación, la clandestino en relación con las prácticas sexuales de los HSH remite no sólo a una opción individual, sino que también expresa una práctica social regulada por el dispositivo normalizador de la sexualidad.

Nuestro objeto de estudio se caracteriza por el sentido que los HSH les otorgan a sus prácticas sexuales realizadas en la clandestinidad. Por ello, se hace necesario explicitar algunas consideraciones sobre el carácter clandestino de ellas.

Según el diccionario de la RAE, el término "clandestino" remite a un conjunto de significados. En primer lugar, el término alude a lo secreto, oculto y especialmente hecho o dicho secretamente por temor a la ley o para eludirla.

Hablar de clandestinidad es evocar lo oculto, lo encubierto, aquello que sucede en las sombras pero que no es necesariamente del todo invisible. Más bien se trata de cosas negadas o al menos no reconocidas. En cierta manera, la clandestinidad se refiere a lo oculto pero sabido: un "secreto público" (Taussig, 1999, en Sutton, 2017, p. 889).

Como vemos, la definición propuesta se ajusta en parte al sentido que les atribuimos a las prácticas sexuales entre HSH como clandestinas. En nuestro estudio, lo clandestino también está connotado por la situación de ilegalidad, ya sea por la coacción de las normas jurídicas o por el imperio de las normas morales que regulan la sexualidad. 
Atribuirles a las prácticas sexuales de los HSH la condición constitutiva de lo clandestino implica resolver algunas paradojas. El hecho de que las prácticas sexuales se realicen en condiciones de ocultamiento o en forma encubierta no implica que ellas necesariamente remitan a espacios privados de intimidad. Una de las características que hemos advertido en la fase exploratoria del trabajo de campo es que la propia dinámica de la vida cotidiana de los varones hace que los lugares de encuentro sexual sean espacios públicos y dentro de horarios rutinarios de la vida social. Por ello, para captar las reglas del campo que regulan las prácticas sexuales entre HSH se planteó la necesidad de efectuar observación participante en sus escenarios naturales.

Las prácticas sexuales entre HSH se producen en situaciones y condiciones de clandestinidad que suceden en espacios públicos y abiertos. Es necesario dar cuenta de instancias de transmutación por las que esos espacios públicos son re-significados y re-apropiados por los sujetos como lugares habilitados para la realización de encuentros sexuales. En otras palabras, los escenarios de encuentro sexual entre HSH están destinados a un uso social específico (un fin sanitario en el caso de los baños o fines recreativos en el caso del Parque); uso que los sujetos subvierten al inscribirle las lógicas, reglas, códigos, rutinas y habitus propios de las prácticas sexuales de los HSH. Así, en un mismo espacio físico, acontece una especie de realidad paralela, en la que algunos sujetos lo utilizan para los fines propios, mientras que otros sujetos lo utilizan simultáneamente para la efectuación de prácticas sexuales clandestinas. Por ello, el investigador tiene que realizar un esfuerzo para escrudiñar lo aparente y decodificar lo que aparece velado en la normalidad de las prácticas.

En nuestro estudio, lo clandestino opera como un dispositivo funcional a la heteronorma. La clandestinidad es el espacio donde se permite seguir el propio deseo, es un ámbito en el que los $\mathrm{HSH}$ experimentan la liberación del orden moral represivo. Pero se trata de un permiso, de una licencia temporal en un espacio intersticial, que a la vez que protege también confina esa experiencia de (seudo) libertad.

En situaciones de clandestinidad no se es más libre ya que en ellas se esconde lo que no se quiere pronunciar. En los espacios y prácticas clandestinas se reafirma el discurso de la anomalía y la transgresión. En lo clandestino puede haber disfrute, pero también hay riesgos. Lo clandestino se vuelve así un escenario de una libertad regulada, vigilada y, a veces, castigada, cuando sale de los límites que trazan su frontera. Y es esa experiencia de libertad la que posiblemente se asocie al goce, ya que hay algo del riesgo de lo clandestino que es en sí mismo erotizante.

Lo clandestino que caracteriza a las prácticas sexuales de los HSH es la condición para su efectivización. Los escenarios de lo oculto propician los movimientos y acciones que permiten el acceso al contacto sexual, en condiciones de paridad con los otros hombres presentes en el campo, resguardando su identidad y las orientaciones consideradas transgresoras de las normas morales.

En el contexto de la clandestinidad estas permisividades se pueden interpretar como acciones que no son impedidas por nadie. Al saberse existentes y contar con cierto grado de permisividad por parte de los guardianes de la moral, se puede difuminar el control sobre ellas. Esta libertad de acción que opera al interior del campo sexual de los HSH sólo se puede percibir si sus prácticas se realizan en lo clandestino, en espacios donde no puedan ser vistas (porque eso implicaría reconocerlas).

Lo clandestino resulta entonces un cuadro ilusorio de una libertad aparente, que está permanentemente regulada, vigilada y controlada a través de mecanismos sutiles que protegen la sexualidad de los HSH del escrutinio público del significado de sus prácticas, en el marco del dispositivo de normalización y moralización sexual. Por ello, la percepción de libertad que pueden tener los $\mathrm{HSH}$ para realizar sus prácticas en los lugares clandestinos sólo se dará si se cumple con la condición de mantenerlas ocultas y silenciadas.

En la apropiación de los espacios en que los HSH llevan a cabo prácticas sexuales en situaciones de clandestinidad, ellos encuentran diferentes estrategias para sobrevivir en lo clandestino. El uso de códigos, reglas, sentidos, placeres y transgresiones a la norma que allí se generan son prueba de ello. Conocer y reconocer esos aspectos requiere una formulación estratégica de acceso al campo.

En resumen, si bien las prácticas sexuales que llevan a cabo los HSH son clandestinas, se desarrollan en escenarios públicos. Es decir, la clandestinidad en sí no está caracterizando el espacio físico como tal, sino 
la realización de prácticas a las que se dota del sentido de clandestinidad. En tal sentido, lo clandestino puede ser entendido como una performance que les permite a los $\mathrm{HSH}$ apropiarse de espacios públicos (baños y parque) en los que hay una fuerte circulación de personas. La elección de esos espacios públicos para desplegar prácticas íntimas sirve como una pantalla para llevarlas a cabo sin ser descubiertos. Lo clandestino como construcción simbólica que resignifica espacios públicos cumple una doble función: por un lado, el sistema de codificación y las formas de acercamiento, intercambio y encuentro sexual sustentadas en la clandestinidad permiten que esas prácticas no sean descubiertas por quienes circulan en los lugares mencionados y no conocen las reglas del juego. Por otra parte, tenemos que los espacios públicos garantizan una mayor circulación de HSH u hombres gays, lo que propicia mayores oportunidades de acceso a otros jugadores del campo y aumenta las chances de intercambio y contacto sexual.

\section{Los Desafíos Metodológicos De LO SEXUAL/CLANDESTINO}

Las investigaciones sobre temas relacionados con la sexualidad suelen ser complejas, en tanto remiten al ámbito de la privacidad de las personas y a la significación que se les asigna a las prácticas sexuales desde los dispositivos socio-culturales que las regulan. En efecto, la sexualidad es una temática que tensiona aspectos morales, culturales y sociales que van más allá del campo científico, por lo que los investigadores sobre estas temáticas muestran una preocupación constante por los aspectos éticos. Además, nuestra investigación debe afrontar el carácter transgresor y abyecto que se les atribuye a las prácticas sexuales entre HSH en situaciones de clandestinidad, lo que constituye un enorme desafío.

Nuestra premisa fue que el enfoque metodológico a adoptar debería garantizar el acceso al propio territorio de las prácticas sexuales de los HSH, para generar la información de un modo "directo". En tal sentido, el enfoque etnográfico nos pareció la opción metodológica más adecuada en tanto que no busca crear o modificar las situaciones, interacciones, habitus y representaciones que configuran las prácticas sexuales clandestinas de los HSH. Por otra parte, diferentes estudios sobre las sexualidades han señalado la utilidad y necesidad de los estudios etnográficos para dar cuenta de la diversidad, heterogeneidad y multiplicidad de prácticas sexuales asociadas a diferentes subculturas de las que son expresión social y política.

La etnografía se nos presenta como la estrategia metodológica más pertinente, en tanto supone que, a diferencia de un diseño experimental, no se aspira a modificar o crear una situación sino, por el contrario, a observar y describir una ya existente. La etnografía, también llamada trabajo de campo u observación participante, puede definirse como "el estudio en profundidad de individuos y grupos en su propio ambiente". (Levine ySkedsvold, 2008, en Santi, 2013a, p. 79).

El etnógrafo, o la etnógrafa, participa abiertamente o de manera encubierta, de la vida cotidiana de personas durante un tiempo relativamente extenso, viendo lo que pasa, escuchando lo que se dice, preguntando cosas; o sea, recogiendo todo tipo de datos accesibles para poder arrojar luz sobre los temas que él o ella han elegido estudiar (Hammersley y Atkinson, 1994, en Santi, 2013b, p. 92).

El trabajo etnográfico implica una apropiación del lugar que opera como escenario de las prácticas sexuales. Supone moverse como uno más en las situaciones, interacciones, rituales y códigos de intercambio. Requiere una actitud de apertura y alerta epistémico para estar abierto a lo que escapa de la mirada. Esa inmersión en el campo de las prácticas sexuales de los SHS requirió de un trabajo de registro, de diálogo, de conocimiento y convivencia con los agentes/practicantes de ese campo. En ese proceso fue relevante no descuidar los detalles, prestar atención a los relatos esporádicos, captar los códigos verbales y no verbales, las formas de relacionarse y las rutinas asociadas a las mismas prácticas sexuales desplegadas en situaciones de clandestinidad.

El campo en el que se despliegan las prácticas sexuales clandestinas y las interacciones situadas de contacto entre los HSH se abordó mediante la observación participante realizada en algunos escenarios identificados previamente. Para obtener la información sobre esos ámbitos de prácticas clandestinas se recurrió a 
informantes clave (personas que asisten a los espacios donde se desarrollan prácticas sexuales entre $\mathrm{HSH}$ ), a información disponible en internet sobre la práctica del cruising en Catamarca y a visitas en diferentes horarios a dichos espacios. Estas acciones fueron realizadas a modo de exploración y reconocimiento del campo, de modo que permitieran definir luego la estrategia de ingreso a cada escenario, la permanencia en él y los modos de registro de información más conveniente.

Las prácticas sexuales clandestinas de HSH siempre han existido. Incluso en Catamarca tienen sus espacios definidos y una serie de códigos que les permiten a los sujetos interactuar de un modo más o menos predecible al interior del campo sexual. Los dos ámbitos que se seleccionaron como escenarios de la observación participante fueron la terminal de ómnibus de la ciudad y el Parque Adán Quiroga. Como veremos posteriormente, ambos espacios son públicos, aunque los escenarios en los que se efectivizan las prácticas clandestinas se circunscriben a ámbitos más acotados dentro de esos espacios.

La observación participante en esos escenarios del campo sexual de los HSH nos ha permitido conocer las dinámicas que se generan en ellos, los códigos que utilizan los practicantes, las formas que tienen de relacionarse, las variantes de prácticas sexuales que se realizan, así como las características propias de los espacios clandestinos. Para el registro de la información se utilizó un registro narrativo que, de acuerdo con Yuni y Urbano, tiene las siguientes características:

[...] presentan la particularidad de que son producidos por el investigador. Constituyen textos en los que se describen acontecimientos, comportamientos de los actores, sentimientos subjetivos del investigador. Mediante las narraciones se intenta describir acciones e interacciones situadas en un contexto y de forma suficientemente comprensiva. Se relatan descriptivamente episodios o anécdotas significativas vinculadas a algún aspecto de la conducta del sujeto observado (2005, p. 173).

Mediante la observación participante realizada en escenarios de prácticas sexuales clandestinas de HSH, se elaboró el registro narrativo tomando en cuenta características espaciales, dinámicas de interacción entre los practicantes, relatos incidentales de situaciones, sucesos relevantes, recurrencias temporales y toda otra información que resultara significativa para la investigación. Utilizaremos parte de esos registros para la construcción de escenas de investigación, que se han presentado como instancias de interpelación de las prescripciones metodológicas.

La investigación de prácticas sexuales que son representadas como abyectas por la moral hegemónica local, así como el carácter ubicuo de sus espacios de realización, nos obligó a pensar en las estrategias de ingreso y las formas en que teníamos que establecer las relaciones con los agentes presentes en el campo. Al respecto, Yuni y Urbano dicen lo siguiente:

En una investigación abierta el investigador debe gestionar la tensión que su presencia produce ante los observados. Por ello es importante aclarar a los actores el sentido de la presencia de quien investiga en el escenario [...] El otro modo de acceder a un escenario es hacerlo de manera encubierta. En estos casos quien investiga asume su rol sin informar a los observados del proceso de investigación (2005, pp. 189-190).

Considerando las características propias de nuestro objeto de estudio, se optó por el acceso encubierto. Siguiendo a los autores citados anteriormente, este tipo de acceso apunta a no alterar la dinámica del campo, ya que la percepción de los HSH de los intereses del investigador representaría una amenaza a los códigos de reserva que estructuran la clandestinidad y dejaría expuestos a quienes la buscan. La adopción de una posición encubierta permitiría observar los espacios clandestinos en su dinámica natural e incluso favorecería el acercamiento a los $\mathrm{HSH}$, con lo que se podría recolectar información de suma importancia para la comprensión de sus prácticas.

Una de las cuestiones recurrentes del método etnográfico remite a los criterios y procedimientos para el acceso al campo. Este momento puede tener mayor o menor dificultad, ya que depende en gran medida de las características socioculturales del escenario, de la naturaleza de las prácticas sociales que se estén estudiando 
y de las singularidades de las instituciones y agentes del campo. Yuni y Urbano plantean algunas cuestiones relacionadas con la accesibilidad y la opacidad en lo que se refiere al ingreso al campo:

La accesibilidad es la disponibilidad para la entrada del observador. La facilidad de acceso estará a su vez condicionada por el tipo de contexto, la posición del investigador y el grado de cumplimiento de las normas de cortesía y la empatía que se establezca [...] Cuando los escenarios comportan un cierto grado de opacidad (espacial, cultural o legal), es necesario arbitrar estrategias de entrada al escenario, ya que éstas tendrán consecuencias directas sobre la cantidad y sesgos -errores- de información que nos proveerá el contexto observacional (2005, pp. 189-190).

La naturaleza de las prácticas sexuales de los SHS nos llevó a advertir que, si bien los escenarios o ámbitos de interacción eran, como se dijo, de carácter público y abierto, la condición de clandestinidad hacía que ellas fueran de difícil acceso. En otras palabras, las prácticas sexuales clandestinas de los SHS se presentan como fenómenos opacos; es decir, se trata de actos, conductas y rituales que no son transparentes ni evidentes para la mirada del observador ingenuo.

La opacidad es entendida como la dificultad para visibilizar algo que no se alcanza a descifrar, ya que, en este sentido algunas conductas o prácticas pueden pasar desapercibidas a los espectadores, si estos desconocen los códigos que les permiten detectar o comprender las conductas (Yuni y Urbano, 2005, p. 189).

En el caso de nuestra investigación, el campo presenta un fuerte grado de opacidad, lo que hace que su inmersión en él, así como el acercamiento del observador a los sujetos, sea dificultoso. Por ello se ha optado por diferentes estrategias metodológicas que permitieran ingresar al campo y recabar información fiable y verídica.

Una de las estrategias fue plantear el ingreso encubierto, posicionando al investigador como un agente más en el escenario, con el propósito de realizar una observación más fluida, sin alteraciones y con un continuo acercamiento a los HSH que circulan en los lugares de observación. El ingreso encubierto al campo ha permitido sostener conversaciones incidentales con los $\mathrm{HSH}$ y reconocer algunos códigos de interacción que nos eran desconocidos.

La actuación encubierta modifica mínimamente las prácticas de los HSH en el campo, en tanto que no perciben la presencia de un extraño con intenciones diferentes de las suyas. Yuni y Urbano plantean: "En una investigación encubierta quien investiga gestiona la información que transmite para conseguir que su identidad social permanezca oculta. Para ello debe tener un buen conocimiento previo de las reglas sociales que rigen en el escenario analizado" (2005, p. 192). Con la información recabada en la exploración de los escenarios se pudieron establecer, en una primera categorización, los horarios de uso clandestino de los espacios por parte de los HSH; los sectores de las localizaciones donde se llevan a cabo los encuentros sexuales y algunas estrategias de ocultamiento o camuflaje que desarrollan los agentes para que dichos encuentros se mantengan en la clandestinidad. Este conocimiento sobre la estructura y dinámica del campo permitió que nos movilizáramos en dichos lugares con mayor facilidad, manteniendo nuestro ingreso encubierto sin mayor dificultad.

La opción por el ingreso encubierto se debe a que en los primeros acercamientos a ambos escenarios se observó que cuando los HSH veían o percibían la presencia de un extraño (entiéndase por tal a aquellas personas que utilizan los espacios públicos para los fines convencionales y de acuerdo con las rutinas de uso propias de su funcionalidad, como higienizarse o realizar necesidades fisiológicas en los baños públicos, o realizar actividades de esparcimiento en el parque), en los espacios mencionados, tendían a modificar su dinámica interactiva y a ocultar toda actividad, para resguardarse de la mirada amenazante de la normalidad.

En el caso de los baños de la terminal, cuando ven que se acerca un policía, un guardia de seguridad o algún empleado de la terminal como el encargado de la limpieza, instantáneamente modifican sus formas de "levante", tomando una posición común del uso del espacio. En el caso del parque Adán Quiroga sucede algo similar: cuando ven la presencia de algún policía en la zona, los HSH se dispersan por los diferentes sectores del parque, ya que la presencia de dichos agentes pone en riesgo su reconocimiento e identificación. 
Transitar los espacios que los HSH utilizan para sus encuentros sexuales de forma clandestina, como uno más en el espacio, nos ha permitido obtener información fiable y de gran utilidad para conocer algunos aspectos de nuestro objeto de estudio, especialmente captar códigos específicos del discurso social. La fiabilidad de la que hablamos se sostiene en la intención de que las prácticas de interacción y registro alteren las dinámicas de las situaciones presenciadas y/o vividas en el campo. Actuar de modo encubierto evita que los HSH muestren una performance producida para resguardarse de la mirada de un extraño, toda vez que atribuyen a su práctica un sentido de transgresión e ilegalidad que los expone a la sanción social y moral.

\section{TENSIONES ÉTICAS EN INVESTIGACIONES SOBRE SEXUALIDAD}

La ética en la investigación es un aspecto de mucha relevancia. Tanto las prescripciones metodológicas como las regulaciones del campo científico destinan una parte de su producción a consideraciones éticas de distinto orden y con diferentes finalidades. En cualquier caso, ambas regulan y delimitan las acciones de los investigadores en el proceso de investigación. Los estudios de sexualidad tienen la particularidad de que tocan aspectos sensibles de la vida de los sujetos y del conjunto social. En el plano individual esos aspectos tienen que ver con la privacidad, la intimidad y la garantía de los derechos personalísimos de los sujetos que deben ser preservados. En lo social, el conocimiento producido por la investigación científica permite la visibilización de sujetos, colectivos y prácticas sexuales diversas. Ese conocimiento socialmente disponible constituye en discurso público aquello que tradicionalmente estuvo al amparo de distintas formas de silencio y de silenciamiento, que pesan sobre todas las prácticas relacionadas con lo sexual. En un contexto conservador como aquel en el que se realiza nuestra investigación, esas tensiones se incrementan, ya que el sentido otorgado a lo sexual como un fenómeno que remite al orden de lo privado y que debe ser silenciado en el discurso público -especialmente cuando se consideran prácticas desviantes de la normalidad- presenta aún mucho arraigo.

Las cuestiones éticas en la investigación social en general, y en los estudios sobre sexualidad en particular, atraviesan todo el proceso metodológico. Las diferentes acciones y procedimientos metodológicas tienen que ser llevados a cabo teniendo como referencia lineamientos éticos. Restrepo define la ética de la investigación de la siguiente manera:

Por ética de la investigación etnográfica me refiero a la reflexión y posicionamiento sobre el conjunto de principios que deben orientar las prácticas asociadas con sus diferentes fases. De ahí que no podemos limitar la ética de la investigación a una fase concreta como el trabajo de campo donde se produce el grueso de los "datos" y donde a menudo se concentran las interacciones con las poblaciones o individuos que estudiamos (2006, p. 87).

Como se refirió en las secciones anteriores, el ingreso al campo de las prácticas sexuales de los HSH no sólo requiere la adopción de estrategias pertinentes, sino que también confronta a los investigadores con cuestiones éticas referidas a los cuidados sobre la información que se obtiene, la identificación de informantes e incluso los potenciales efectos correctivos o punitivos ante el develamiento de ciertas prácticas. No menos importante es el papel de la ética en lo atinente al resguardo de la integridad y respeto que se debe tener en torno a quienes proporcionan dichas informaciones, ya sea de manera directa o indirecta.

$\mathrm{Al}$ referirse a las cuestiones éticas sobre el trabajo de campo en la investigación etnográfica, Restrepo señala que una de sus preocupaciones es cuando se da "la situación de una abierta actitud de intromisión de un investigador foráneo y aparentemente recién llegado [...] lo que provoca que el sujeto presente en el campo sienta la agresión [...] al ser convertido en un objeto para la mirada del investigador" (2016, p. 84). Tomando en cuenta lo que dice el autor, creemos que el ingreso encubierto en cierta forma permite reducir la sensación de intromisión y agresión que pueden experimentar los $\mathrm{HSH}$, ya que al presentarse de este modo y sostener una presencia en el escenario se vuelve parte de las interacciones cotidianas. 
Restrepo critica "la investigación etnográfica de estilo extractivista que tiene como propósito sacarles a las personas, a como dé lugar y lo más rápido posible, la información requerida por este etnógrafo, las cuales son reducidas a fuentes de extracción de datos" (2006, p. 85). La perspectiva extractivista devela una posición ética del investigador, en la cual los sujetos son tratados como meros objetos proveedores de información. Por el contrario, nos posicionamos en un lugar en el que, además del reconocimiento de las personas que deciden vivir parte de su sexualidad en la clandestinidad, apostamos a que la producción de conocimiento sobre sus prácticas permita desarrollar propuestas que representen una contribución para la mejora de las situaciones adyacentes y la reducción de las situaciones de riesgo que se asocian a ellas.

En la actualidad, son numerosas las reservas legales y protocolarias en relación con los aspectos éticos y bioéticos en la investigación social, y especialmente respecto de la investigación con sujetos. Nuestro estudio requiere tener presentes los elementos éticos, ya que la sexualidad es una temática atravesada por diferentes aspectos morales, culturales y normativos, cuyo abordaje se hace aún más complejo. Restrepo realiza un listado de recomendaciones sobre la ética en la investigación social de tipo etnográfica, las que se consideraron inicialmente pero que fueron interpeladas en el pasaje del proyecto de trabajo a la ejecución del trabajo de campo.

Nuestro objeto de conocimiento presenta algunas características que tensionan dichas prescripciones metodológicas. Las más relevantes que hemos señalado refieren a lo clandestino como rasgo de la naturaleza de las prácticas sexuales de los HSH. También operan las representaciones sobre la sexualidad y su consideración como un asunto del ámbito privado y, por lo tanto, un acto perteneciente al ámbito de la intimidad y la privacidad personal, lo que implica dificultades generadas por la opacidad como fenómeno. Un tercer aspecto remite al uso de los espacios públicos por parte de los HSH para sostener prácticas sexuales clandestinas.

Nuestra intención es mostrar algunas contradicciones éticas que hemos vivenciado en los primeros acercamientos al campo y que nos obligaron a pensar en otras formas de llegar al escenario y de relacionarnos con los agentes que circulan en él. La selección de los espacios de observación se debe a que en ellos se concentra la mayor circulación de HSH. Estos escenarios resultan propicios para abordar las prácticas sexuales en condiciones y situaciones de clandestinidad, en tanto que los $\mathrm{HSH}$ concurren a ellos por diferentes motivos, como ocultamiento, erotización o circulación de otros hombres, entre otros. La concurrencia a estos espacios de encuentro opera en muchos casos como una opción que les evita exponerse socialmente a través de la utilización de otros medios de contacto (como aplicaciones informáticas) o la concurrencia a lugares de esparcimiento destinados a público gay.

Los acercamientos a los informantes en los escenarios de observación se dan de manera incidental. Cada uno de los escenarios presenta particularidades propias de su materialidad y de su uso social habitual. Por ejemplo, en la terminal de ómnibus la permanente circulación de personas en tránsito durante el día permite el enmascaramiento de las prácticas de identificación, cortejo y contacto en espacios-tiempos acotados y de mayor riesgo de exposición. En el caso del Parque Adán Quiroga, la amplitud del espacio, la densidad de la forestación y las variantes lumínicas hacen que sea de mayor uso en el horario nocturno y que las prácticas de interacción y contacto impliquen en muchos casos la utilización de distintos tipos de vehículos. En cada uno de los escenarios, la peligrosidad de las prácticas clandestinas presenta variantes que han debido considerarse para preservar incluso la integridad de los investigadores. Por ejemplo, en el Parque es mayor el grado de exposición a riesgos de violencia física o de robo, mientras que en la Terminal las situaciones se vinculan más a la exposición y la violencia de los agentes de seguridad y vigilancia.

A continuación se contrastan algunas de las prescripciones éticas planteadas por Restrepo con escenas de situaciones extraídas de los registros de campo realizados en los baños de la terminal de ómnibus (BT) y el Parque Adán Quiroga (PAQ). Esta operación de contrastación pretende ilustrar el tipo de tensiones que deben resolver los investigadores en un estudio sobre sexualidad connotado por la clandestinidad. Para efectuar la contrastación, reproduciremos el enunciado del autor y luego presentamos viñetas extraídas de la bitácora del trabajo de campo, por lo que el lector encontrará registros de observaciones o de interacciones 
con otras personas redactados en primera persona. Posteriormente, se formulan algunos comentarios que ponen el foco sobre aspectos específicos.

No es adecuado formular una investigación que signifique poner en riesgo a la gente que participaría del estudio (Restrepo, 2016).

Nuestro estudio se propone indagar las situaciones de riesgo que experimentan los HSH y cuáles de estos se asocian a sus prácticas sexuales. Los HSH viven en constante riesgo en los espacios que utilizan para sus encuentros sexuales. El carácter clandestino de sus prácticas sexuales los pone en ese estado que los vuelve propensos a sufrir agresiones por parte de otros hombres o de los agentes de "control" del lugar (policías, guardias de seguridad, personal de limpieza, etc.). En estos espacios también encontramos que existen otros peligros vinculados a la salud física y mental de los $\mathrm{HSH}$, los que pueden estar más relacionados con las situaciones que configuran la cotidianeidad de las prácticas sexuales realizadas en esos escenarios. La variedad de situaciones que implican la exposición a diferentes tipos de riesgos pueden observarse en algunos fragmentos de nuestros registros.

\section{Escena 1}

Para tratar de indagar un poco sobre el tema de la protección le pregunté si por lo general traía preservativo para ese tipo de encuentros, a lo que respondió; "No, Sería muy arriesgado que mi novia por ahí me encuentre forros. Siempre las personas con las que me encuentro por ahí traen forros”. Le pregunté: “¿Estarías sin preservativo en el caso que la persona con la que te encuentres no trajera?", su respuesta fue la siguiente; “Depende, si la persona me da confianza, o por ahí solo sería un pete”.(05/12/2018, Parque Adán Quiroga).

\section{Escena 2}

Se observó que en algunos momentos pasaban patrullas [policiales] e ingresaban al centro del parque. Solo hacían recorridos. Sin embargo, se notaba un mayor patrullaje sobre el área trasera, que es donde se observaban más encuentros de hombres que tienen sexo con hombres (10/01/2019, Parque Adán Quiroga).

Escena 3

Entré al primer baño, en el cual hay una pared con un hueco realizado manualmente que da vista al segundo. Cuando ingreso y me asomo por el orificio, vi que el chico más joven le hacía sexo oral al hombre mayor. Escuché que el hombre se refería al chico como una mujer: le decía frases como las siguientes: "Sí, princesa, chupala toda”, "Te gusta, mujer”, de cierta forma feminizando al chico. Pasaron unos minutos y el hombre mayor penetró al chico joven sin preservativo [...] (12/01/19, Baños Terminal).

\section{Escena 4}

Dos policías municipales, junto al guardia de seguridad de la terminal, increparon a un HSH y le dijeron:

"Salí de ahí, te estás haciendo el boludo, vigilando a la gente. Te estoy viendo desde hace rato."

El hombre señalado le respondía: "Nada que ver, estoy vomitando..."

"No te hagas el boludo, sé que estás viendo a los vagos que entran. Desde hace rato que te estoy vigilando."

[Decidí sólo escuchar la conversación y no mirar por el orificio del cubículo, para no arriesgarme a que me dijeran algo a mí]

Uno de los policías, con voz muy alterada y violenta, le dijo:

"Así que estás viendo pijas, puto, putos de mierda. Te vamos a llevar por estar acosando gente y mirando pijas, puto."

El hombre le respondió [asustado]: "Le juro que no estaba haciendo nada, estaba vomitando. Tengo dos hijos y son huérfanos. Por favor, no me haga esto, déjeme ir. Y usted [le dijo al guardia] me ha visto porque yo vivo por la 9 de Julio, por ahí nos hemos visto. No estaba haciendo nada, por favor.”

El mismo policía [no había escuchado la voz del tercero] dice: "Aquí no es para andar mirando pijas, puto, te vamos a llevar." (12/02/2019, Baños Terminal).

Las escenas que hemos planteado dan cuenta de diferentes riesgos a los que están expuestos los HSH: algunos referidos a la situación contextual, otros a las prácticas en sí y otros a los efectos de la asunción de riesgos potenciales. Estos riesgos son una condición intrínseca de la práctica que se analiza. Las prácticas sexuales entre varones, y más aún las que se llevan a cabo en espacios públicos, llevan una fuerte carga de estigma cuando son expuestas. Erving Goffman nos dice: 
El [...] estigma [...] hace referencia a un atributo profundamente desacreditador; pero lo que en realidad se necesita es un lenguaje de relaciones, no de atributos. Un atributo que estigmatiza a un tipo de poseedor puede confirmar la normalidad de otro [...] Y nos dice que existen tres tipos de estigma: abominaciones del cuerpo, defectos del carácter del individuo: creencias, homosexualidad, perturbaciones mentales, etc., y estigmas de la raza, nación y religión. (2006, pp.13-14).

De acuerdo con la definición del autor, encontramos que las prácticas sexuales entre varones entrarían en el imaginario social en las de tipo "defectos del carácter del individuo". Tanto la escena 2 como la 4 revelan que, si bien las prácticas sexuales de los HSH se desarrollan en la clandestinidad, existe un conocimiento de ellas por parte de las autoridades que regulan y preservan la "normalidad" de dichos espacios. Siguiendo al autor, esta "permisividad" a medias se debe a que los grupos dominantes, o los sujetos que asumen su superioridad genérica o moral, requieren de esas otredades para confirmarse constantemente como la normalidad. De hecho, los registros evidencian que el rasgo de afirmación remite a la masculinidad hegemónica que apela a la feminización como inferiorización para la consumación del acto sexual, o a la estigmatización de masculinidades no hegemónicas que se expresa en el uso del colectivo "putos de mierda".

Otro elemento que emerge de los registros citados es la dependencia de la acción del sentido de vigilancia de la mirada externa y los riesgos que dicha vigilancia implica para la exposición en caso de que esa práctica y sus agentes sean develados. En la escena 1, la vigilancia está en la mirada de la novia, mientras que en las otras la mirada de control es la de las fuerzas de la ley. Aunque las prácticas sean clandestinas y se produzcan en condiciones de ocultamiento, no dejan de ser reguladas, vigiladas y controladas. Los espacios de clandestinidad expresan cierta permisividad para la realización de las prácticas sexuales de los $\mathrm{HSH}$, aunque su naturaleza clandestina reafirma el carácter estigmatizante de la acción y deposita en el agente el estigma de la desviación y la abyección, por lo que debe preservarse de ser descubierto para evitar la sanción y el juicio público.

Finalmente, las situaciones de riesgo asociadas a las prácticas sexuales clandestinas suponen que el propio investigador disponga de recursos y habilidades que aseguren su integridad, a la vez que le permitan preservar su actuación encubierta. La habilidad de sostener una conversación que lleva a un HSH a explicitar sus prácticas de cuidado en una situación de cortejo en un vehículo (escena 1) o de camuflarse en una situación de requisa (escena 4) son una muestra de la necesidad de que el investigador en el trabajo de campo domine las reglas del pasaje de la clandestinidad a la normalidad, y viceversa, para preservarse. En definitiva, se trata de sostener una actuación como investigador que se mueve en el borde lo visible/lo opaco, lo accesible/lo clandestino, circulando y revirtiendo las reglas que permiten la transmutación de lo clandestino a lo lícito.

No es ético adelantar investigaciones de manera oculta o secreta sin el conocimiento ni consentimiento de las personas que estudiamos (Restrepo, 2016).

Ya hemos mencionado que uno de los primeros requerimientos estratégicos para lograr el ingreso al campo y realizar una observación participante que no se vea sesgada por la presencia invasiva del investigador nos llevó a optar por el ingreso en forma encubierta. En referencia a esto, Yuni y Urbano plantean:

lo encubierto [...] es una práctica que plantea serios problemas éticos a algunos científicos sociales, aunque otros argumentan que, al informar a los observados, muchos aspectos de la conducta humana quedan oscurecidos como consecuencia de que las personas observadas intentan ofrecer una imagen adecuada de sí mismos (2005, 189-190).

El requerimiento planteado por Restrepo colisiona con la necesidad de que la presencia y la mirada del investigador no sean percibidas como amenazantes o que se les atribuyan sentidos de vigilancia o exposición. En esos casos, el resultado sería la alteración de las dinámicas de intercambio de los HSH, lo que provocaría que la información recabada mediante la observación participante y los registros incidentales presenten un marcado sesgo, producido por el intento de protegerse de la mirada invasiva generada por la presencia de un extraño en el contexto de lo clandestino. De hecho, consideramos que, en el caso del abordaje de prácticas sexuales clandestinas a través de la observación participante, el investigador tiene que instrumentar estrategias de acción encubierta. 
Escena 5

Algo interesante es que pude pasar como uno más del lugar, ya que mi presencia no alteró en lo absoluto la práctica de estos HSH. Pasa lo contrario cuando se siente la presencia de algún auto, patrulla o moto, ya que eso sí altera las dinámicas del lugar por temor a que sea la policía (26/04/2019, Parque Adán Quiroga).

Escena 6

En un acercamiento incidental, un chico de 19 años me abordó y me dice;

Sujeto: "Hola, ¿̨cómo andás, qué hacés?"

Yo: "Bien, aquí dando la vuelta, haciendo un poco de ejercicio. ¿Vos?"

Sujeto: "Viendo que surge... Te voy a decir la posta, a mí me gusta culiar y que me chupen el pingo los putos" [aclara] "pero me gustan las mujeres."

Yo: [risas] "¿Y por qué te gusta culiar putos y que te la chupen?"

Sujeto: "Los putos son muy zarpados, me piden cosas como que les pegue o gritan mucho, y chupan muy bien el pingo." Yo: “'Y cómo tiene que ser el puto para que te guste?"

Sujeto: "No cualquier puto, tiene que ser limpito. Los travas no me gustan porque se prostituyen y por ahí son sucios. También me gusta que huela bien, y que esté bien vestido No me gustan los putos de la calle. Vos estás bien” [haciendo referencia a que yo le gustaba]. "Sabes yo tengo el pico grande y me gusta disfrutar, sentir placer."

Yo: “¿Sentís mucho placer con un puto?”

Sujeto: “Me gustan más las mujeres porque tienen más lugares para hacérselo. Tienen tres agujeros”, [aclara].

Yo: "¿Y si te pintaría hacer algo conmigo?"

Sujeto: "Sí, de una."

Yo: “¿Utilizas forro?"

Sujeto: “Casi nunca. Yo le tiro la leche donde usted quiera.” (08/06/2019, Parque Adán Quiroga).

Ambas escenas muestran el resultado que produce el ingreso encubierto en el tipo de interacción con los sujetos. La escena 5 es un registro reflexivo en el que se da cuenta de la autoevaluación positiva con respecto a la inserción en el escenario y la naturalización de la presencia del investigador en la dinámica relacional, contrastándola con los cambios que produce la circulación de otros agentes sociales percibidos como amenazantes. Por un lado, tenemos que la dinámica de los espacios observados no se altera y por otra parte vemos que "actuar como uno más" propicia acercamientos incidentales que permiten obtener información más confiable en tanto que los $\mathrm{HSH}$ suponen que el investigador es uno más del espacio, que tiene sus mismas intenciones (encuentro sexual). Esta estrategia que hemos tomado contradice la prescripción metodológica de Restrepo, ya que en esas situaciones no es posible pedir el consentimiento a las personas, ni tampoco es conveniente explicitar los motivos de la presencia del investigador en el campo. En ciertas ocasiones ha sido posible explicitar el motivo de la presencia en el campo, lo que habilitó luego la realización de entrevistas o de conversaciones más estructuradas en las que se solicitó el consentimiento.

No se pueden sacar fotografias y videos sin el consentimiento y conocimiento de las personas que estudiamos, a no ser que sean acontecimientos públicos donde los participantes suponen que esto sucede (Restrepo, 2016).

Los estudios sobre sexualidad han indagado frecuentemente en los espacios públicos utilizados como lugares de encuentro clandestino relacionados con prácticas homosexuales. En esos trabajos, los baños públicos o teteras han recibido especial atención (Rapisardi y Modarelli, 2001) y, en ellos, las escrituras del espacio y los objetos. Siguiendo esa tradición metodológica, y verificando que, en Catamarca, los baños de la Terminal de Ómnibus configuraban un circuito de levante de los HSH, se decidió abordarlo como un escenario de observación. En un primer momento se elaboró un croquis de los baños para luego relacionarlo con diferentes prácticas y rutinas de uso clandestino. En esa instancia se advirtió la proliferación de escrituras en paredes y puertas de los baños, por lo que se decidió efectuar un registro fotográfico de ellas.

Escena 7

Se tomaron registros fotográficos de las puertas y paredes de los cubículos que se encuentran en los baños de la terminal.

Dichos baños se encuentran ubicados sobre el ingreso de la calle Vicario Segura (03/12/2018, Baños Terminal).

En los registros fotográficos podemos encontrar algunos de los siguientes enunciados: 


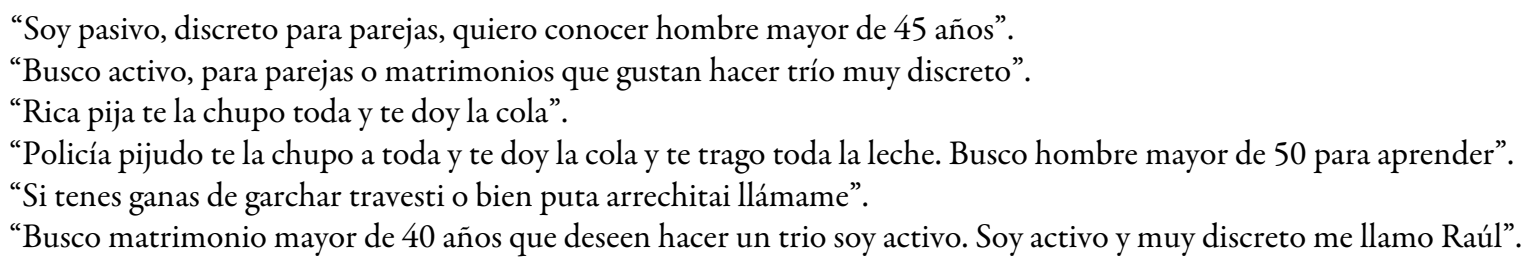

(Casi todos los letreros incluyen números telefónicos).

Escena 8

Pasado un tiempo llega un hombre de aproximadamente unos 28 años e ingresa al primer cubículo. Yo tenía un pedazo de papel en el orificio mayor que se encuentra en la pared entre el primer y el segundo cubículo. En un momento veo que la persona que se encontraba en el primer cubículo sacó el papel y metió su pene en el orificio y empezó a penetrarlo (metiendo y sacando su pene). Cabe destacar que esta práctica es conocida en otros países o grandes ciudades como glory hole o agujero anónimo (México) y nos parece interesante su aparición en un espacio público supuestamente conservador, lo que demuestra que posiblemente la conformación del campo clandestino se alimenta de informaciones sobre prácticas homosexuales globalizadas a través de la pornografía. Esta situación resulto muy incómoda porque la persona lo seguía haciendo aun cuando no recibía respuesta de mi parte. Tomé una fotografía de dicha escena y decidí salir del lugar y sentarme nuevamente en la banca de afuera (09/02/2019, Baños Terminal).

El registro fotográfico es fundamental para la descripción de los espacios y la verificación de información contenida en los informes de campo. Sin embargo, se plantearon varios dilemas con respecto a su uso como evidencia material en la comunicación de los resultados. Por ejemplo, en la estancia en el baño ha sido interesante observar los renovados intentos del personal de seguridad de obturar el "agujero anónimo" (lo que es otro indicio del reconocimiento de las prácticas que allí se producen). Ese proceso de apertura/ obturación/reapertura/nuevas obstaculizaciones de la pared de mampostería que separa dos baños se ha registrado fotográficamente como evidencia de los intentos de obstaculizar las prácticas sexuales que allí suceden. No obstante, las fotos tomadas en escenas como la descrita en la escena 8 no serán utilizadas en los informes. Si bien esas fotografías no violan la identidad de los sujetos que exponen sus partes íntimas en espacios públicos, entendemos que no aportan más que una descripción que permita dar cuenta de ciertos rituales, prácticas y modalidades de contacto sexual entre HSH.

En el caso de las fotografías de inscripciones en las paredes se optó por enmascarar las imágenes, en tanto que la mayoría de ellas incluyen números telefónicos, nombres o direcciones de correo electrónico. Esas informaciones podrían violar el derecho a la intimidad e integridad de las personas y también pondrían en riesgo la integridad física del investigador. No obstante ello, entendemos que la propuesta de Restrepo de brindar información a los sujetos sobre la realización de registros fotográficos o la toma de videos no sería pertinente para nuestro trabajo.

Si bien las prácticas sexuales desarrolladas en estos escenarios son de carácter clandestino, no podemos obviar que para la lógica normativa o del sentido común los baños y el parque son espacios públicos. Ello nos habilitaría a realizar el registro fotográfico siempre y cuando se mantenga protegida la identidad de los sujetos. En nuestro caso, hemos decidido realizar registros mecánicos sólo de los espacios para documentar aspectos estructurales del escenario u obtener evidencia de lenguajes, códigos y discursos. Por el contrario, decidimos no fotografiar ni filmar a los sujetos tanto en las interacciones directas como indirectas, así como de los sujetos en situación de realización de prácticas sexuales. De hecho, nuestra posición como observadores y las estrategias de camuflaje adoptadas nos hubiesen permitido efectuar registros de esas acciones mediante el teléfono, pero consideramos que era más importante preservar la identidad de los sujetos que circulan en cada escenario. Por ello, decidimos autolimitar la utilización de dichos registros y plantear su uso sólo si generan un aporte relevante para la investigación.

Cambio de nombres, el uso de seudónimos, la transformación de lugares y tiempos que permitan identificarlos, son algunas de las estrategias para el anonimato que deben implementarsepara proteger a laspersonas (Restrepo, 2016). 
En el mismo sentido, al referirse al trabajo etnográfico Santi advierte:

Una preocupación central en el trabajo de campo es la protección de la confidencialidad de la información brindada por los o las participantes u obtenida como fruto de la observación [...] en ocasiones es imposible despojar la investigación de aquella información que puede resultar en la identificación de los o las participantes o del lugar donde se realizó el estudio (Santi, 2013b, p. 87).

De acuerdo con los que nos plantean ambos autores, la confidencialidad de la información obtenida es una preocupación central en el trabajo de campo. Se propone el uso de seudónimos o la modificación de características físicas o de personalidad de los agentes que circulan en el campo, y que elaboren descripciones generales que no permitan la identificación de los espacios de visita. En relación con estas recomendaciones, nuestra investigación es problemática, en tanto que muchas de esas características personales o ambientales son centrales para la identificación de patrones de cortejo, interacción e intercambios dentro del campo de las prácticas sexuales de los HSH. Por ejemplo, la reconstrucción de las características físico-espaciales de cada escenario permite identificar los circuitos de contacto, los espacios de intercambio sexual, los códigos asociados a diferentes rituales de prácticas clandestinas o el uso diferencial del espacio según características o condiciones de los sujetos. Para ello se hace necesario registrar en la bitácora croquis o mapas, ya que dicha descripción se vuelve necesaria para reconstruir las prácticas en situación.

Escena 9

En ese momento ingresa al cubículo un hombre de aproximadamente unos 40 años, con bermuda, ojotas, remera musculosa y gorra negra. De un aspecto aparentemente varonil (barba, caminar recto, fornido). Deja la puerta abierta. En ese momento uno de los chicos que se encontraba en los mingitorios (gordito, con barba, ropa holgada, de aproximadamente unos 20 años) miraba hacia el cubículo. La posición de los pies y piernas del hombre que entró al cubículo eran paradas frente a los mingitorios como si estuviese mostrando algo al chico joven que también se encontraba en el último mingitorio (09/02/2019, Baños Terminal).

Escena 10

Pasé por el lugar donde estaba sentado el sujeto y en ese momento ya se encontraba de pie. Pasé aproximadamente a un metro de distancia y me di cuenta que era un señor de aproximadamente unos 50/55 años de edad, vestía una camisa manga larga de cuadritos (no pude distinguir los colores) un jean y zapatos altos, con lentes y poco cabello. Él me miró y se tocó los genitales, pero yo seguí caminando (04/03/2019, Parque Adán Quiroga).

\section{Parque Adán Quiroga (demarcación territorial de la zona donde circulan los $\mathrm{HSH}$ )}

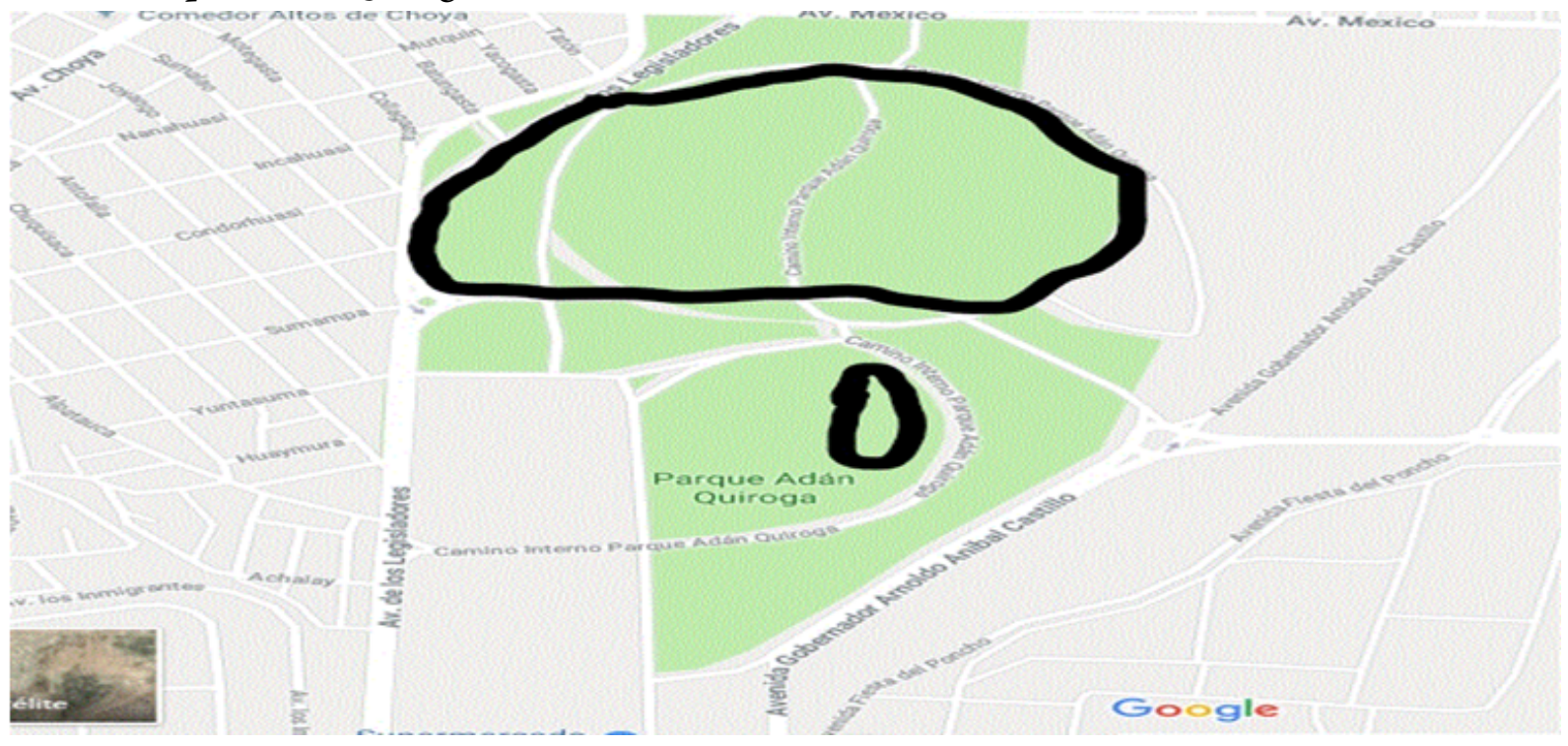

La demarcación más amplia es el sector de menos circulación publica, donde se concentra más el contacto sexual entre HSH, y el sector más pequeño demarcado al centro es la parte más iluminada del parque y con mayor circulación de familias (Fotografía extraída de google maps. Demarcación de elaboración propia de los autores). 
Como puede observarse en las escenas, las descripciones de las características físicas y de comportamiento de los HSH permiten identificar códigos de reconocimiento, pautas de insinuación y signos que evidencian la dinámica que llevan a cabo en los lugares de encuentro sexual. En nuestro estudio, uno de los puntos de mayor tensión ética de la descripción a través de croquis es la visibilización de estos espacios públicos como escenarios de prácticas sexuales clandestinas, lo que puede generar el despliegue de procesos de vigilancia o represión, orientados a la restitución de la normalidad y rectitud moral de esos escenarios.

[A] Los investigadores de la sexualidad, [...] se les acusa rápidamente de conductas inadecuadas o poco éticas; y que su carácter, motivaciones y métodos se examinan más profundamente que los investigadores de otros campos (Fahs et al., 2017; Irvine, 2014; Thomas \& Williams, 2016 Van Den Hoonaard, 2011, en Webber y Brunger, 2018).

La referencia de estos autores es interesante porque llama la atención respecto de los prejuicios que pesan sobre los aspectos éticos de las investigaciones sobre sexualidad. En tal sentido, podría pensarse que el intento de desacreditar o poner en duda la veracidad de los registros del trabajo de campo o apelar a la transgresión de parámetros éticos no serían más que artilugios metodológicos que pretenden cuestionar la cientificidad de los estudios. Como lo señalan Webber y Brunger (2018), otro aspecto ético es el que tiene que ver con la distancia que debe de guardar el investigador en relación a su objeto de estudio, ya que de dicha distancia dependerá la objetividad de la información recolectada. En relación con este requerimiento ético encontramos otra tensión en el campo de prácticas, ya que cuando investigamos lo sexual entre varones (en relación con lo clandestino y el riesgo) no sólo es necesario el acercamiento a los sujetos sino también la interacción en situaciones de cierta cotidianeidad para ellos. Además, la evaluación de la calidad de la información que se obtiene en el campo requiere de la reflexión constante acerca del grado de implicación que experimenta el investigador en esos acercamientos, especialmente cuando se ponen en juego situaciones de empatía, de cortejo, de insinuación o de expresión de deseo o rechazo por parte de los interlocutores. Obviamente, esas situaciones surgen de la actuación encubierta de los investigadores, por lo que la propia reflexividad y los intercambios intersubjetivos con los otros investigadores trazan los límites éticos. Esa tarea de reflexividad mediada por la vigilancia epistemológica intersubjetiva permite dialogar con lo que observamos, lo que sentimos, lo que nos produce el trabajo de campo, para posteriormente dirimir y seleccionar estrategias y modos de interacción y acción que provean información fiable, sin transgredir pautas consideradas no éticas en la investigación,

La posición encubierta con la que hemos ingresado a campo, el habitar y dialogar con los mismos códigos que ahí se utilizan, ser un clandestino más en la clandestinidad, ha permitido mayores acercamientos con los HSH y tener una movilidad más fluida en los espacios observados. Por ejemplo, los registros sobre encuentros incidentales con algunos sujetos han permitido clarificar algunas dudas sobre ciertos códigos y representaciones construidos previamente a la realización del trabajo de campo. A su vez, estos acercamientos han permitido tomar nota de diferentes barreras que dificultarían la participación de los HSH en una entrevista formal o han posibilitado identificar diferentes tipos de prácticas sexuales clandestinas sobre las que se puede indagar con más profundidad con otras estrategias de recolección de datos. La comprensión de los cuidados y estrategias que los HSH ponen en juego para no ser descubiertos contribuyó en gran medida a la obtención de pistas que permitieron la descripción densa de las prácticas sexuales clandestinas y a la orientación de las acciones a desplegar en las instancias de observación.

Escena 11

Salí a la banca que da justo al frente de los baños para evitar confrontaciones con la seguridad del lugar, quienes estaban revisando constantemente. Al sentarme en la banca podía observar un chico que, cada vez que entraban personas al baño, se acercaba al espejo y se ponía a usar su celular. Cuando las personas salían ingresaba de nuevo, ya sea al área de mingtorios o cubículos, pero durante casi una hora esa fue la dinámica que podía observar (11/12/2018).

Escena 12

Cuando crucé la avenida me percaté que un chico joven que andaba en bicicleta (de aproximadamente unos 25 años) cruzó la avenida y se dirigió hacia la parte donde se encuentra más oscuro y [en la] que se observa sólo monte (arbustos, 
yuyos, árboles). Detrás del chico iba otro chico (de aproximadamente unos 30 años), a una distancia de 50 metros aproximadamente; los seguí sin que se dieran cuenta, en un momento los perdí de vista (21/01/19).

Estas escenas muestran algunas estrategias que utilizan los HSH para resguardar su identidad y mantener sus prácticas sexuales en condiciones de clandestinidad en espacios públicos.

García (2019, p. 74)señala que "Cunliffe y Alcadipani (2016) resaltan la importancia de visibilizar y problematizar el acceso al campo, el tránsito que este experimenta y lo que conllevan las negociaciones con los participantes". En la clandestinidad, el investigador tiene que volverse clandestino, para interactuar en una dinámica que no altere la naturaleza de las interacciones entre los agentes. Tiene que volverse parte del espacio y a veces tiene que cruzar las fronteras de lo permitido para habitar esos espacios comprendiendo sus códigos y haciendo uso de ellos. Sólo así se puede comprender lo que realmente sucede en campo.

Estas acciones no sólo tienen consecuencias positivas sobre la calidad de los datos, sino que también pueden acarrear implicancias negativas, en tanto que el investigador puede ser estigmatizado al atribuírsele la condición de HSH. En este sentido, Erving Goffman afirma que "el individuo estigmatizado, por un lado, se convierte en desacreditado cuando supone que su calidad de diferente ya es conocida, y desacreditable, cuando su condición de diferente no es conocida aún. Pero existe la posibilidad de serlo” (2006, p. 14). Así, la posición del investigador en el campo y su grado de implicación con los sujetos y las prácticas clandestinas lo convierten en un potencial sujeto desacreditable, tanto con los actores del mismo campo como para el contexto social más amplio.

Una mirada retrospectiva de los diferentes momentos vividos en el trabajo de observación denota la presencia de algunas huellas que han ido delimitando nuestra aproximación al objeto de estudio. Dicha delimitación no es producto de la casualidad, sino que hubo interpelaciones, miedos, pérdidas, cercanías e identificaciones que, de cierta forma, lograron la movilización para elegir e investigar sobre las prácticas sexuales de riesgo de los HSH en contextos de clandestinidad.

El acceso al campo ha tenido ciertas ventajas ya que, previamente a realizar las observaciones, ya se tenía conocimiento sobre los lugares de encuentro de los HSH. En el caso de uno de los investigadores se realizó una aproximación a los escenarios, aunque no con fines de investigación, sino por cuestiones relacionadas con la curiosidad y el morbo que le producía pensar en las prácticas sexuales clandestinas como algo prohibido que tensiona los aspectos morales y normativos de un contexto tan conservador como el catamarqueño.

Más que un acceso "virginal", el acceso al campo fue marcado por una experiencia previa, no sólo en lo que refiere al conocimiento del lugar, sino también al contacto personal, y en ocasiones íntimo, con algunos $\mathrm{HSH}$, que fueron relatando los lugares, las formas de relacionarse, los códigos, sus deseos, erotizaciones, etc. Entonces, ¿cómo pensar en una distancia "objetiva” con el "objeto"? Como dijimos previamente, el camino de la objetivación no ha sido el de poner entre paréntesis nuestros valores, ideologías e identidades genérico-sexuales. Por el contrario, optamos por la vigilancia intersubjetiva entre los investigadores, lo que ha permitido comprender las implicaciones de las identificaciones, los riesgos y posibilidades de los modos de acercamiento con los HSH o los restos emocionales de las variadas experiencias vividas en el campo de las prácticas sexuales clandestinas. Este trabajo de vigilancia intersubjetiva nos permitió sostener el encuadre metodológico.

Las estrategias adoptadas para el ingreso al campo no sólo generan ventajas respecto a la obtención de información. Ser uno más del espacio implica también la exposición a riesgos a los que están expuestos los HSH. Como investigador encubierto es inevitable asumir dichos riesgos, ya que de eso depende la credibilidad y aceptación por parte de los HSH como uno más en su dinámica clandestina.

Escena 13

Un sujeto en una moto se paraba en diferentes puntos de ese mismo camino, pero no se acercaba a nadie: sólo observaba. Cuando me retiro de ese espacio del parque, me dirijo nuevamente al espacio principal donde se encuentra el circuito. Ahí me pude percatar que el mismo sujeto de la moto se movió a esta parte del parque y se estacionó detrás de un árbol que se encontraba al lado del circuito, pero en la oscuridad. De acuerdo a los movimientos en distintos puntos del parque de 
dicho sujeto, puedo suponer que estaba en búsqueda de algún encuentro sexual o buscaba alguna oportunidad para robarle a alguien $(02 / 03 / 2019, \mathrm{PAQ})$.

Escena 14

Para hacer un poco de tiempo me senté sobre un depósito de agua que está entre la parte principal y el inicio de la parte trasera del parque marcada en el mapa. Transcurridos unos minutos, se me acercó un chico de aproximadamente unos 18 años, delgado, ropa holgada, gorra [...] me preguntó:

Sujeto x: "¿Tenés fuego?"

Yo: "No, no tengo, amigo."

Sujeto x: "¿Vos te culiás putos?"

Yo: "No. ¿Y vos?"

Sujeto x: "No, tampoco. Los cago choriando."

Yo: "Ah, todo bien."

Sujeto x: "Nos vemos, chango, seguiré buscando fuego." (04/03/2019. PAQ).

Escena 15

Quien se encarga del guardaequipajes en ese horario, un hombre de aproximadamente 45 años, me miraba fijamente. Seguramente porque me ve seguido en el lugar y puede llegar a imaginar que también hago uso de los baños con fines sexuales $(20 / 05 / 2019, \mathrm{BT})$.

Las escenas descriptas muestran algunos de los riesgos y miradas a los que se expone el investigador en un campo de prácticas en situación de clandestinidad actuando en un rol encubierto. Ser parte de la dinámica natural de la clandestinidad conlleva asumir todo lo que sucede en el espacio, compartiendo los códigos e interacciones de los HSH desde una supuesta intencionalidad compartida y un dominio de las reglas que regulan ese campo de prácticas sexuales.

\section{Conclusiones}

Son variados los aportes que aparecen en la literatura metodológica en referencia a lo que implica el trabajo de campo en los estudios de sexualidad y la importancia de tomar recaudos metodológicos y éticos para su realización. Por ejemplo, Webber y Brunger (2018) hablan de los riesgos que se producen en el trabajo de campo en este tipo de investigaciones y lo que implica pensar en algunos aspectos éticos. Por su parte, García (2019) reflexiona sobre las implicaciones del investigador en el trabajo etnográfico en una investigación sobre sexualidad y cómo se sobrellevan dichas implicancias tanto en las interacciones con los sujetos en el campo, así como en el momento de analizar los datos. Figari, Pecheny y Jones (2008) aportan múltiples y variadas sugerencias metodológicas producidas en su amplio recorrido de estudios sobre las prácticas sexuales entre varones. En el caso de Figari, en sus estudios sobre lo que denomina heterosexualidad flexible, se refiere a algunas estrategias metodológicas para el ingreso a campo. Al mismo tiempo, enriquece sus discusiones sobre aspectos que remiten al trabajo etnográfico y a la importancia de los estudios emergentes en dichos escenarios. Por su parte, Pecheny ha desarrollado estudios relacionados con la sexualidad de varones y el impacto de la epidemia del VIH sobre grupos vulnerables. Principalmente analiza a los HSH, quienes son nuestro objeto de estudio (En Cáceres, Pecheny, Terto, 2002).

Todos los aportes citados han sido de gran ayuda para comprender la complejidad de los estudios de sexualidad tanto a nivel conceptual como metodológico. En algunos casos, esos aportes adoptan una posición crítica frente a las prescripciones metodológicas de los estudios sociales y culturales a la vez que exploran alternativas metodológicas ancladas en un modelo de co-investigación o de investigación militante (entendida esta como la que acompaña y sostiene las demandas de los movimientos de los colectivos sexuales minorizados y/o subalternizados).

En nuestro trabajo nos hemos topado con algunas dificultades y dilemas que habían planteado algunos de los autores a los que nos referimos previamente. No obstante, muchas de esas producciones reconstruyen los 
escenarios de prácticas sexuales a través de relatos obtenidos en entrevistas o de fuentes indirectas. En nuestro caso, el nivel de opacidad del fenómeno generado por las características culturales del contexto local nos llevó a optar por la observación directa de algunos espacios de práctica sexual entre $\mathrm{HSH}$, sabiendo de antemano que no son los únicos, pero que en ellos se pueden reconstruir con mayor fidelidad las lógicas de lo clandestino que operan en la fachada de los espacios públicos y abiertos.

Por otra parte, pretendemos recuperar desde lo dilemático algunos aportes de la discusión contemporánea sobre las metodologías que abordan las sexualidades en diálogo con las perspectivas conceptuales de los feminismos, los estudios críticos de la sexualidad y los estudios decoloniales (De Otto 2017; Sutton 2017). Las tensiones teórico-metodológicas vinculadas a los aspectos éticos de la investigación de prácticas sociales clandestinas, ilegales o ilícitas, han sido registradas en diferentes estudios sociológicos y antropológicos a lo largo del siglo XX.

En ese período, las prescripciones y recomendaciones éticas formuladas por los teóricos de la metodología de la investigación social muestran un sesgo hacia los valores sociales hegemónicos. En el caso del estudio de las sexualidades, la realización de estudios “científicos" no estuvo exenta de una base moralista que contribuyó al apuntalamiento del dispositivo normalizador de la sexualidad. Sin embargo, las transformaciones epistémicas producidas por los enfoques teóricos contemporáneos pusieron en cuestión las prescripciones metodológicas sustentadas en las tradiciones hegemónicas de las ciencias sociales.

Muchos de los aspectos que se han planteado en este trabajo adquieren sentido en un ejercicio de reflexividad y de interpelación a algunos supuestos metodológicos que siguen regulando el campo de producción de conocimientos sociales. Como hemos señalado, el estudio de prácticas sexuales clandestinas contiene una doble carga de estigmatización, en tanto que la sexualidad continúa siendo un objeto de estudio que debe resistir los intentos de silenciamiento, invisibilización y descalificación científica (como lo hacen los defensores de la ideología de género), a lo que debe agregarse el carácter clandestino de las prácticas entre $\mathrm{HSH}$, que tensiona de un modo singular los imaginarios heteronormativos y la masculinidad hegemónica.

Las prácticas socio-sexuales de HSH están fuertemente signadas por la clandestinidad, aunque gran parte de ellas se despliegan en espacios públicos y en tiempos sociales de vida cotidiana como el horario comercial, administrativo o recreativo, a plena luz del día. Lo clandestino sucede ante nuestras propias narices y en ámbitos de masividad o circulación intensiva. Penetrar en ese cono de sombra en el que se configuran los encuentros entre HSH implica adoptar no sólo una posición teórico-metodológica, sino también un compromiso ético-político que permita advertir, decodificar y recodificar desde los registros de campo las opciones diversas de ejercicio de la sexualidad masculina.

Las recomendaciones metodológicas tradicionales crujen cuando las confrontamos con las demandas del trabajo de campo en el que se afronta el riesgo de generar situaciones que perjudiquen a quienes interactúan en esos espacios de clandestinidad. No es lo mismo estudiar la sexualidad en escenarios abiertos que investigarla en esos espacios que tienen cierto grado de "opacidad", y que requieren de otras formas de ingreso e interacción.

Este carácter dual que pone en interacción lo clandestino con lo público nos ha generado una serie de desafíos éticos que hemos planteado anteriormente. Sin embargo, en el contexto local es imposible dejar de pensar en las implicancias que estas descripciones traerían para los HSH que asisten a dichos lugares al hacerlas de público conocimiento o ante la posibilidad cierta de que el ojo disciplinador de la moral sexual abandone su actitud permisiva, para adoptar una más represiva.

Tal como surge de algunos relatos historizantes de las prácticas sexuales obtenidos en entrevistas con $\mathrm{HSH}$, en caso de que eso ocurriera los escenarios de prácticas sexuales mudarán de lugar, de modalidad y de rutina, tal como ya ha sucedido antes. Nuevamente, aparece otra arista de lo sexual clandestino como objeto de conocimiento: se trata de un fenómeno que remite a lo oculto, aunque paradójicamente existe un conocimiento social circulante, un saber que en general no pasa al discurso público, que está naturalizado como parte de las licencias de la masculinidad y que muta y transmuta en diferentes momentos históricos. 
No obstante, es necesario recordar que el interés por las prácticas sexuales de los HSH no persigue un propósito voyeurista como cientistas sociales, sino que entendemos que las situaciones que impone la clandestinidad implican en sí mismas condiciones de riesgo para la salud individual y configuran un riesgo para la salud pública. Por otro lado, asumimos que es probable que la clandestinidad y el riesgo que conllevan las prácticas sexuales en esas condiciones sean elementos constitutivos del placer que se obtiene en su realización.

En la valoración de las alternativas para lograr una comprensión de los sentidos que los HSH construyen respecto de los riesgos intrínsecos de sus prácticas sexuales, a las que las condiciones de clandestinidad les imprimen sus propios riesgos, decidimos que por lo menos una parte del estudio adoptara un enfoque directo de interacción en los escenarios naturales de encuentros sexuales. De acuerdo con ese posicionamiento, las estrategias de ingreso y permanencia en el campo se orientaron a la construcción de intercambios basados en la "naturalidad" para lograr acercamientos y diálogos incidentales con diversos tipos de HSH. Los diálogos incidentales han sido de suma importancia, ya que han brindado información de reglas, normas, valores y lenguajes que escapan a la observación y a la vez iluminan el sentido de ciertas prácticas.

El ingreso encubierto a los escenarios de observación ha obligado a repensar también la forma de indagar los aspectos de nuestro interés. Refiriéndonos a ello, hemos sugerido que "otro modo de construir las relaciones de campo consiste en buscar similitudes biográficas entre observador y observado, pues esto contribuye a crear la sensación en el informante de que 'el ajeno' no es tan distinto como parece" (Yuni y Urbano, 2005, p. 190). La autorreferencia a experiencias personales similares a las que viven los HSH pretendía establecer un clima de confianza para que el sujeto que abordamos sintiera que se podía expresar ante un igual con quien compartir códigos, deseos e intenciones. La información obtenida en estos acercamientos ha sido muy valiosa para nuestros registros narrativos, ya que da cuenta de la dinámica del campo, descripta y enunciada por los mismos agentes que la protagonizan.

El conocimiento previo del campo fue un recurso para movernos en el lugar y reconocer algunos códigos que posteriormente utilizamos para reforzar el rol encubierto. Ese recurso ha permitido establecer algunos recaudos orientados a preservar la integridad del mismo investigador. Como sostiene Peterson, "la actividad puede volverse peligrosa ya que no somos conscientes de las reglas o códigos de conducta a su alrededor" (En Webber y Brunger, 2018, p.7).

El ingreso encubierto al campo puede suscitar una serie de cuestiones que ponen en riesgo la integridad del investigador, principalmente ante la presencia de fuerzas de seguridad que, como hemos descripto, no tienen criterios adecuados a la hora de poner al descubierto las prácticas sexuales de los $\mathrm{HSH}$. Por eso se recomienda la confección y utilización de una credencial, en la que se establezca la institución de pertenencia, número de contacto con el director de dicha institución, fotografía y nombre del proyecto de investigación. En caso de extrema necesidad esa documentación puede ser presentada y de esa forma justificar la presencia continua del investigador en los espacios de observación.

El abordaje de prácticas sexuales clandestinas confronta al investigador con dilemas respecto a lo que está bien y lo que está mal, lo que es ético y lo que no lo es, más allá de los protocolos y normas éticas. Las características de nuestro objeto de estudio, lo sexual/clandestino, nos obligaron a reflexionar permanentemente sobre el marco estratégico del trabajo de campo, ya que, en un principio, " en una investigación como la señalada, la cuestión ética pasea por terrenos pantanosos cuando la relación con el campo no se limita temporalmente a encuentros puntuales y acotados, sino que excede los límites de la implicación académica" (García, 2019, p. 84). La estancia permanente en el escenario y la inmersión en su cotidianeidad hacen que entre los clandestinos nos volvamos cercanos, aunque desconocidos; nos encontramos en esa cotidianeidad del campo, compartiendo experiencias, estrategias y códigos. Quien investiga en esos terrenos pantanosos no puede eludir las interpelaciones sobre los sentidos y alcances de su práctica científica. 
Otro aspecto a tener en cuenta es la importancia del involucramiento en las interacciones que tenemos con los sujetos en el campo. La condición de habitualidad que genera la permanencia en el escenario nos permite generar lazos o acercamientos para acceder a información relevante. A su vez, esa implicación produce un lastre emocional que el investigador debe gestionar. Además de permitirnos sentir, vivir y experimentar el modo en que nos afectan los otros y sus prácticas, es necesario objetivarlas para someterlas a un proceso de reflexividad intersubjetiva con los demás integrantes del equipo.

En nuestra investigación encontramos dos tipos de dilemas que, aunque son de naturaleza distinta, encuentran su relación en la incidencia que ambos tienen sobre el trabajo de campo. El primero hace referencia a la naturaleza del objeto, en tanto que las prácticas sexuales de riesgo de $\mathrm{HSH}$ en situaciones de clandestinidad convocan simultáneamente a lo sexual y a lo clandestino. Ambos aspectos presentan diversas regulaciones, no sólo de tipo normativo sino también del orden moral, lo que hace que nuestro objeto sea complejo y requiera de tratamientos específicos como los que hemos mencionado.

El segundo dilema tiene que ver con los lineamientos éticos planteados en las prescripciones metodológicas. Los elementos éticos se tensionan constantemente con los aspectos que caracterizan nuestro objeto de estudio (clandestino, sexual, público, sexo entre hombres), lo que convierte las reflexiones éticas en un componente nodal en los procesos de construcción de conocimiento sobre las sexualidades.

Frente a las dificultades que se desprenden de esos dilemas propios de la clandestinidad/lo sexual, encontramos que las alternativas más eficaces (en el sentido de aquellas acciones que conducen a la obtención de nuestros propósitos) podrían resumirse en algunos criterios: en lo clandestino nos volvemos clandestinos; en nuestras formas de interacción en el campo tensionamos la lógica de reducir al otro a un mero objeto proveedor de información, para reconocerlo como un agente que con mayor o menor implicación es coconstructor y facilitador de los conocimientos científicos; en la oscuridad, entre el frío, los arbustos, el ojo policial, la distancia de un mingitorio a otro, entre un baño y otro, construimos relaciones, intercambiamos simbolismos, ejecutamos códigos. Allí, en la transgresión a esos límites, se encuentra el verdadero sentido de las prácticas, de lo que nos interesa conocer.

Atravesar en ocasiones la frontera construida por las prescripciones metodológicas autorizadas ha implicado sentir, reír, temer, abrazar, escuchar, generar lazos, vivenciar placeres y sufrir displaceres. Habitar el campo de lo clandestino/sexual significa reconocer al otro y reconocernos como otro; siendo un extranjero entre los extranjeros; transgrediendo fronteras que abran paso al acceso de información relevante, para conocer lo que desconocemos. Y que aquello desconocido sea el punto de partida para recorrer itinerarios de elucidación que abran intersticios de re-conocimiento que permitan generar factores de oportunidad.

\section{ReFERENCIAS}

Cáceres, C., Pecheny, M., y Terto J. (2002). Sida y sexo entre hombres en América Latina: vulnerabilidades, fortalezas y propuestas para la acción -perspectivas y reflexiones desde la salud pública, las ciencias sociales y el activismo. Perú: UPCH/ONUSIDA.

De Otto, A. (2017). Metodologías en contexto: intervenciones en perspectiva feminista, poscolonial, latinoamericana. Ciudad Autónoma de Buenos Aires. Argentina: CLACSO.

García, A. (2019). Evocando deseos y revolviendo malestares: la im-pertinencia de las emociones en mi trabajo etnográfico. Revista Antipoda España, 35. Recuperado de https://dialnet.unirioja.es/servlet/articulo?codigo=7 018962

Goffman, E. (2006). Estigma: la identidad deteriorada. Buenos Aires: Amorrortu.

Guzmán, F. (2010). Los claroscuros del mestizaje: negros, indios y castas en la Catamarca colonial. Córdoba: Encuentro Grupo Editor-Facultad de Humanidades-UNCA. Recuperado de http://sedici.unlp.edu.ar/handle/10915/33 826

INADI, y UNCA. (2012). Mapa nacional de la discriminación. Catamarca Argentina. 
Núñez, G. (2007). Masculinidad e intimidad: identidad, sexualidad y sida. Hermosillo Sonora México: Porrùa.

Pecheny, M., Figari, C., Jones, D. (2008). Todo sexo es politico, estudios sobre sexualidades en Argentina. (1 ra ed.). Buenos Aires Argentina: libros del zorzal.

Ponce, E.; Machado, H y Perea, J. (2012). Paisajes en disputa. Una cartografia de la conflictividad social en la Provincia de Catamarca (2001-2004). Córdoba: Facultad de Humanidades-UNCA.

Rapisardi, F. y Modarelli, A. (2001). Fiestas, baños y exilios. Los gays porteños en la última dictadura. Buenos Aires: Editorial Sudamericana. Recuperado de http://repositorio.filo.uba.ar/handle/filodigital/8285.

Restrepo, E. (2016). Etnografía: alcances, técnicas y éticas. Colombia: Envion.

Santi, M. (2013a). Ética de la investigación en ciencias sociales: un análisis de la vulnerabilidad y otros problemas éticos presentes en la investigación social. UBA. Argentina. Recuperado de http://dspace5.filo.uba.ar/bitstream/handl e/filodigital/1638/uba_ffyl_t_2013_se_santi.pdf?sequence=1\&isAllowed=y.

Santi, M. (2013b). La ética de la investigación social en debate: hacia un abordajeparticularizado de los problemaséticos de las investigaciones sociales (Tesis de maestría). Argentina. Recuperado de repositorio digital FLACSO Ecuador.

Sutton, B. (2017). Zonas de clandestinidad y nuda vida: mujeres, cuerpo y aborto. Revista de estudios feministas. Brasil, 25(2). Recuperado de https://www.scielo.br/scielo.php?pid=S0104026X2017000200889\&script=sci_abstrac t\&tlng=es.

Yuni, J., y Urbano, C. (2005). Mapas y herramientas para conocer la escuela: investigación etnográfica e investigaciónacción. Argentina: Brujas.

Webber, V., y Brunger F. (2018). Assessing Risk to Researchers: Using the Case of Sexuality Research to Inform. Research Ethics Board Guidelines. Estados Unidos de America, 19(3). Recuperado de https://www.qualitative-r esearch.net/index.php/fqs/article/view/3062.

\section{NoTAS}

1 Se realizaron observaciones participantes en dos espacios públicos, que fueron seleccionados por ser utilizados por los HSH como lugares de encuentro sexual en situación de clandestinidad. Dichos espacios son los baños de la terminal [En el texto aparece con inicial mayúscula] (ubicados en el acceso que se encuentra sobre la calle Vicario Segura) y el Parque Adán Quiroga. Las visitas a dichos lugares se realizaron en diferentes horarios de concurrencia de público (mañana, tarde y noche). Cada observación tenía una duración aproximada de entre 2 a 3 horas, durante las fechas que comprende el período de diciembre del 2018 a junio de 2019. Se realizó un registro narrativo sobre cada visita a los espacios mencionados.

2 Hace referencia a una persona que esta con ganas de tener sexo. 